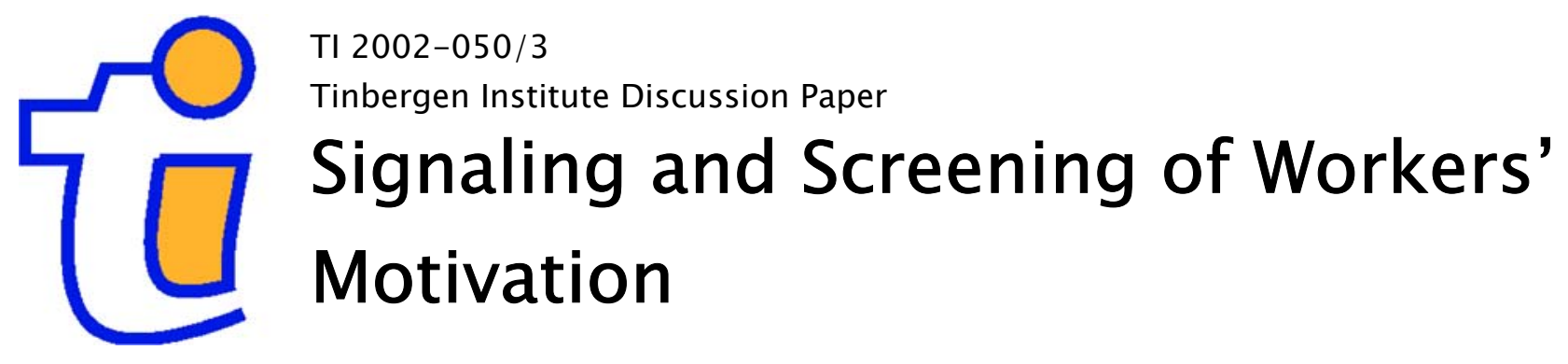

Revised version: February 2005

Josse Delfgaauw

Robert A.J. Dur

Department of General Economics, Faculty of Economics, Erasmus Universiteit Rotterdam, and Tinbergen Institute. 


\section{Tinbergen Institute}

The Tinbergen Institute is the institute for economic research of the Erasmus Universiteit Rotterdam, Universiteit van Amsterdam, and Vrije Universiteit Amsterdam.

Tinbergen Institute Amsterdam

Roetersstraat 31

1018 WB Amsterdam

The Netherlands

Tel.: $\quad+31(0) 205513500$

Fax: $\quad+31(0) 205513555$

Tinbergen Institute Rotterdam

Burg. Oudlaan 50

3062 PA Rotterdam

The Netherlands

Tel.: $\quad+31(0) 104088900$

Fax: $\quad+31(0) 104089031$

Please send questions and/or remarks of nonscientific nature to driessen@tinbergen.nl.

Most TI discussion papers can be downloaded at http://www.tinbergen.nl. 


\title{
Signaling and Screening of Workers' Motivation
}

\author{
Josse Delfgaauw and Robert Dur \\ Tinbergen Institute, Erasmus University Rotterdam*
}

February 2005.

\begin{abstract}
This paper develops a model in which workers are heterogeneous in their intrinsic motivation to work at a firm. We characterise optimal incentive schemes and examine how the firm can attract and select highly motivated workers to fill a vacancy when workers' motivation is private information. While posting a higher wage increases the probability of filling the vacancy, it decreases the expected average quality of job applicants, because a higher wage induces workers who are less motivated to apply. The optimal wage scheme entails a trade-off between the probability of filling the vacancy, the rents left to the worker, and the expected motivation of the selected worker.
\end{abstract}

Keywords: Signaling and screening models; Intrinsic motivation; Monetary incentive schemes; Wage posting; Minimum wage.

JEL codes: D82, J31, J42, M51, M52.

${ }^{*}$ Corresponding address: Josse Delfgaauw, Tinbergen Institute, Erasmus University, P.O. Box 1738, 3000 DR Rotterdam, The Netherlands. E-mail: delfgaauw@few.eur.nl; dur@few.eur.nl. 


\section{Introduction}

Economic models of worker behaviour typically assume that people dislike working. Hence, in order to induce workers to exert effort, employers must provide external incentives. Employers have different means to increase workers' effort. For instance, the introduction of pay-for-performance devices will induce employees to work harder. Equivalently, closer monitoring of workers' effort, accompanied by sanctions (e.g. dismissal) in case of shirking, will also result in higher effort.

Empirical research suggests that the standard neoclassical view of worker behaviour is often too narrow. Agell and Lundborg (1999) report results of a survey among managers in Swedish manufacturing and conclude that "much recent theorizing about effort and incentives is potentially misplaced [because] most managers appear to ascribe a more important motivational role to psychological and sociological factors than to economic sticks and carrots" (p. 25). Interviews with US managers by Bewley (1998) yield corresponding results. Rather than monetary incentives, managers emphasize that work should be interesting and stimulating, that workers should feel involved in decision-making, and that workers' achievements are noticed and appreciated. ${ }^{1}$ One Swedish manager responded that "people work hard as long as they have fun".

Surveys among employees also indicate that monetary rewards are of much less importance for job satisfaction and workers' effort than postulated in economic analysis. For instance, in a 1977 survey of the US labour force, half of the respondents agreed with the statement that "what I do at work is more important to me than the money I earn", and more than 90 percent stated that they put in more effort into their job than required (Quinn and Staines, 1979). Even though we should be cautious (or even suspicious) about stated preferences, the results of these surveys suggest that a large part of the labour force is motivated at work by more than just monetary rewards (Baron, 1988).

The observation that workers may provide effort for non-pecuniary reasons has two important implications. First, monetary incentive schemes designed to motivate a 'standard neoclassical worker' may be suboptimal. Second, when people differ in their motivation, the performance of a firm may become dependent on its capability to select the 'most motivated' candidate among job applicants.

This paper relaxes the standard assumption in the economic literature that people dislike working to study these issues. We develop a model in

\footnotetext{
${ }^{1}$ Bartram et al. (1995) asked 498 small business in the UK which qualities of young workers they regard as important. The employers ranked 'interest in the work' third, just below 'honesty an integrity' and 'conscientiousness', and just above 'general personality' and 'motivation and drive', all with average ratings above 3.4 on a 4-point scale. General ability, educational qualifications and work experience were considered less important.
} 
which workers to a certain extent like to exert effort at the workplace. Hence, people like their job, not only because they get paid, but also because they enjoy working. Whereas this type of motivation has for long been virtually absent in mainstream economics, psychologists have argued that people undertake many activities without expecting an extrinsic reward. 'Intrinsic motivation' is considered to be of major importance for human behaviour (see e.g. DeCharms, 1968, Deci, 1971, and Furnham, 1990).

Recently, a few papers in economics have studied wages and incentive schemes when workers are intrinsically motivated (Benabou and Tirole, 2003, Besley and Ghatak, 2004, Francois, 2000, and Glazer, 2004). The main distinguishing feature of our paper is that we allow workers' motivation to be private knowledge. As a result, the firm can not select the best-motivated worker among the job applicants. Hence, an adverse selection problem arises. We show that it may be in the interest of the firm to offer a low wage so as to discourage relatively low motivated workers from applying. This comes at the cost of a higher probability of leaving the vacancy unfilled. The optimal wage scheme entails a trade-off between the probability of filling the vacancy, the rents left to the worker, and the expected motivation of the selected worker.

People may be intrinsically motivated to work for different reasons. One might simply like to undertake certain activities. The activities which are intrinsically valued, and hence the evaluation of intrinsic qualities of different jobs, may vary across people. A motivated veterinary surgeon is not likely to be motivated to work as a butcher. Intrinsic motivation is not solely determined by persons, jobs, or firms, but by combinations of certain people and certain jobs or firms.

Intrinsic motivation may also be related to 'self-esteem', broadly defined as how people think about themselves. Thus, people may be intrinsically motivated to work (or to refrain from shirking), because it makes them think better about themselves. Self-esteem may be enhanced by working or refraining from shirking in general, but it may also be related to particular kind of jobs. For instance, workers in hospitals may feel that they contribute to a goal which is considered to be 'good'. Dixit (2002) notes that organisations that serve an idealistic or ethical purpose may be particularly attractive for people who share these goals. Obviously, which goals are considered to be 'good' may differ among individuals.

Regardless of the precise reason for the enjoyment of or satisfaction from work, the baseline is that people can derive utility from working. The presence of intrinsically motivated workers has important implications for firms. Motivated people probably work harder, which increases output. And because people derive utility from the job, they may be willing to work for a lower wage. People will take job satisfaction into account when deciding on whether to accept or reject a wage offer. A higher wage at another job may not compensate for the loss of intrinsic qualities of the job. 
We develop a model in which workers are heterogeneous in their intrinsic motivation to work at a particular firm. Working at the firm has some unique trait which is valued differently by different workers, giving the firm monopsony power. ${ }^{2}$ We study two issues. First, we examine the implications of workers' intrinsic motivation for optimal monetary incentive schemes. We extend a standard incentive wage model and show that - in line with Dixit - motivated workers work harder and, for a given level of effort, are willing to work for a lower wage. The higher the firm's bargaining power, the more it can extract the motivational rents from the worker. When the firm has sufficient bargaining power, a more motivated worker brings about higher output and, under a mild condition, lower wage cost. We also show that when the firm has a decreasing returns to effort production technology, monetary incentives are weaker, the more motivated its workers.

Second, we examine how the firm can attract and select highly motivated workers to fill a vacancy. We assume that each worker has positive probability of observing the vacancy. The workers who observe the vacancy decide whether or not to apply, taking application cost into account. We consider three cases which differ in the assumption made about the observability of applicants' motivation. We start with the assumption that the firm can observe the motivation of applicants. Next, we consider the case where the firm can not observe the motivation of the applicants. Lastly, we allow the applicants to credibly signal their motivation to the firm.

We will show that in all of these cases, it is optimal for the firm to commit to a minimum wage offer, either because commitment resolves the Diamond paradox (Diamond, 1971) or because it avoids a lemons problem (Akerlof, 1970). When motivation of applicants is observable to the firm, the firm hires the worker with the best motivation among those who applied. The profit-maximising level of the minimum wage is determined by the tradeoff between wage cost and the probability of filling the vacancy. When motivation is unobservable, there is an additional selection effect. A higher minimum wage decreases the expected quality of job applicants, as it induces less motivated workers to apply for the job. Hence, the probability that a highly motivated worker is selected decreases. However, if applicants can signal their motivation to the firm, a commitment to a minimum wage gives them an incentive to reveal their motivation, which eliminates the selection effect.

The different assumptions about the observability of applicants' motiva-

\footnotetext{
${ }^{2}$ Manning (2003, p. 4) argues that heterogeneity in workers' preferences is one of the three most plausible sources of frictions in the labour market, giving firms monopsonistic power. Monopsony power arises naturally when intrinsic motivation is firm-specific. Dixit argues that 'company spirit' in private firms and the idealistic purpose served by a public agency may motivate agents. When intrinsic motivation is related to an occupation rather than to working at a particular firm, monopsony power arises only if there are no other firms (in the neighbourhood) offering similar jobs.
} 
tion may reflect different screening technologies employed by firms, ranging from application forms and job interviews to work trials and the use of assessment centres (see Keenan, 1995, and Bartram et al.). The use of tests in the screening process has increased substantially over the last decades (Jenkins, 2001). The 'personality and workstyle questionnaire' has become one of the most widely used test types (Ryan et al., 1999). While these findings may suggest that firms have ample opportunities to determine applicants' motivation, the performance of applicants in such tests may be subject to their choice of effort and behaviour, implying that applicants may have a choice whether or not to reveal their motivation to the firm.

The paper is organised as follows. Section 2 discusses the related literature. Section 3 examines the implications of workers' intrinsic motivation for optimal monetary incentive schemes. In Section 4 we study how the firm can attract and select highly motivated workers to fill a vacancy, assuming that the firm can only offer a fixed wage. Section 5 generalises the results of Section 4 to the case of optimal monetary incentive schemes, as studied in Section 3. Section 6 concludes.

\section{$2 \quad$ Related Literature}

Intrinsic motivation has, until recently, been largely ignored in economic analysis, with the exception of the work by Bruno Frey (see among others Frey, 1993, 1997a, and 1997b). We differ from his work in our focus on sorting and selection issues. Moreover, we abstract from the possibility that external incentives crowd out a worker's intrinsic motivation. Therefore, in our model, it is always in the firm's interest to provide monetary incentives, even when a worker is highly motivated. However, high wages reduce the average intrinsic motivation among the pool of job candidates, and may thus reduce labour productivity unless the firm can fully observe applicants' intrinsic motivation.

The idea that, all else equal, workers are willing to work for a lower wage at jobs with intrinsic qualities traces back to Adam Smith's Wealth of Nations. The theory of equalising differences (Brown, 1980, Rosen, 1986) states that all (dis)amenities of a job are reflected in its wage. Several studies suggest that the opportunity to contribute to the goals of a nonprofit organisation is valued by workers and may explain the wage differential between non-profit and for-profit organisations (see e.g. Hansmann, 1980, Preston, 1989, Frank, 1996, and Rose-Ackerman, 1996). Recent empirical evidence is provided by Leete (2001) and Frey, Kucher, and Stutzer (2001). This paper contributes to this literature by examining the effect of intrinsic motivation on optimal pay-for-performance schemes and on recruitment and selection of job applicants.

Most of our analysis focuses on the case where workers' motivation is 
unobservable to the firm. Hence, our model is a principal-agent model where the agent (the worker) has private information about his type. Benabou and Tirole, by contrast, focus on the case where the principal has private information about the attractiveness of the job to workers. The choice of the wage scheme by the principal may then signal his private knowledge to the worker. As a result, extrinsic rewards may either crowd in or crowd out intrinsic motivation. Several recent papers study incentive provision to intrinsically motivated workers, among others Besley and Ghatak, Francois, and Glazer. In these papers, as in ours, firms have all the bargaining power. In contrast to our paper, these papers assume that the firm can observe workers' intrinsic motivation. ${ }^{3}$

Our analysis builds on signaling and screening models of the labour market. A seminal paper in this field is Spence (1973), and a recent survey of the literature is Riley (2001). Most studies focus on screening of workers' abilities. The setup of our model is closely related to the ability-models. As in our model, firms must commit to pay high wages to induce workers to signal their type. An important difference between the ability-models and our model is that motivation not only affects worker's productivity, but also his willingness to work. Moreover, our model departs from the standard screening model by assuming that the firm faces several job applicants, among which it chooses, as in Janssen (2002). The standard model considers the case of one worker and two firms, see Cho and Kreps (1987).

Our work is also related to the job search literature, in particular to directed search models (see e.g. Burdett, Shi, and Wright, 2001, and Shi, 2002). Montgomery (1991) argues that firms that face high cost of leaving a vacancy unfilled offer higher wages. The reason is that workers send an application with higher probability to firms that offer higher wages. Hence, firms increase their probability of filling the vacancy by posting a higher wage, as in our model. Another common element is that workers base their application decision on the probability of getting the job, which depends on the expected total number of applicants for this job.

Closest to our paper is Handy and Katz (1998). They study a model in which potential employees differ in both ability and motivation. While the firm can test for an applicant's ability, it can not distinguish motivated from unmotivated workers. Handy and Katz show that to promote self-selection among potential employees, the firm has an incentive to commit itself to pay a low wage. By committing to pay a low wage, the firm is certain that a job applicant is a motivated worker. Our analysis differs from theirs in various respects. First, we assume that the firm can not draw on an infinitely large pool of applicants consisting of all types of workers. In our model, the firm

\footnotetext{
${ }^{3}$ The kind of intrinsic motivation that we focus on in this paper differs from an intrinsic motivation to behave reciprocally, as studied by Akerlof (1982) and Falk et al. (1999), or intrinsic feelings of altruism towards one's colleagues or boss, which is studied by Rotemberg (1994).
} 
can not be certain that the worker who is most motivated for the job has observed the vacancy and, hence, is in the pool of job applicants. Therefore, a commitment to pay the lowest possible wage (the wage which is acceptable only to the most motivated worker in the economy) is in general not optimal for the firm. For it precludes hiring a worker who is somewhat less motivated when the most motivated worker in the economy is not available. Hence, the firm optimally sets a minimum wage which attracts workers with different - albeit high — levels of motivation to apply for the job. Second, Handy and Katz do not consider the decision of potential employees to apply for a job. We show that their results depend on the assumption that application costs are zero. Positive application costs, however small, imply that a maximum wage is of no avail, whereas a minimum wage helps to attract and select highly motivated workers. Application costs are likely to be positive, given the time and effort involved in writing an application, having job interviews, and possibly performing tests, attending an assessment centre, or even undertaking a work trial. Lastly, our analysis allows for signaling by workers and offering performance pay by firms.

\section{Optimal Monetary Incentive Schemes for Moti- vated Workers}

This section explores the implications of workers' intrinsic motivation for the optimal design of monetary incentive schemes. The literature (see e.g. Lazear, 1995) usually assumes a worker's utility function of the form:

$$
U[w(e), e]
$$

where utility is concave in income $\left(U_{1}>0, U_{11}<0\right)$, income depends on effort according to the wage scheme $w(e)$, and the cost of exerting effort is convex $\left(U_{2}<0, U_{22}<0\right)$. We introduce intrinsic motivation by adding a third argument to the utility function: ${ }^{4}$

$$
U\left[w(e), e, \gamma_{i} e\right]
$$

where $\gamma_{i} \in[0, \bar{\gamma}] . \gamma_{i}$ measures the degree to which worker $i$ is intrinsically motivated, which varies between different kind of jobs. The positive utility derived from effort is assumed to be concave in $e\left(U_{3}>0, U_{33}<0\right) .{ }^{5}$ Hence, apart from an indirect effect of effort on income through the wage scheme, utility first increases in effort and then, starting from some level depending

\footnotetext{
${ }^{4}$ Without significant loss of generality, we introduce intrinsic motivation as a third argument in the utility function - and not as a modification of the second argument - for ease of exposition.

${ }^{5}$ Constant, or even increasing, marginal positive utility from effort does not affect the results as long as optimal effort is finite (i.e., we abstract from 'workaholics'). We also assume $U_{3}>-e \gamma U_{33}$, a condition that will be discussed below.
} 


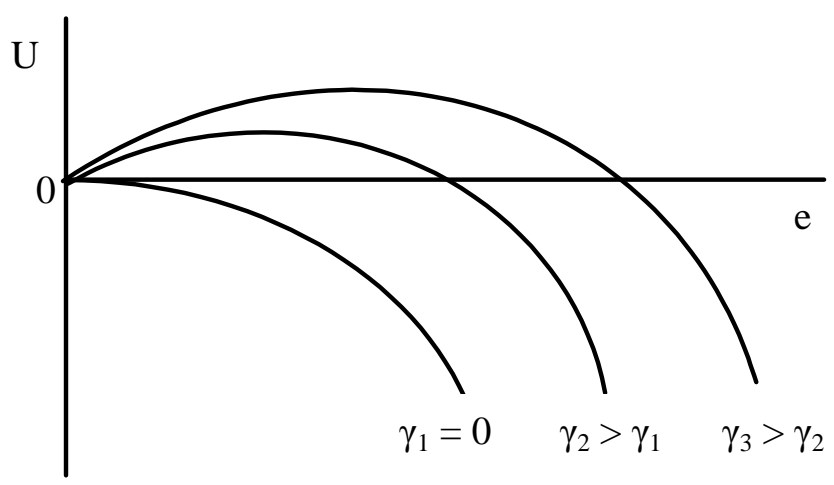

Figure 1: The effect of intrinsic motivation on the direct utility of effort

on the value of $\gamma_{i}$, starts decreasing, see Figure 1. Depending on the level of $e$, total utility derived from exerting effort may be positive or negative. For convenience, we assume that all cross-derivatives are zero: $U_{i j}=0$ for all $i \neq j$.

The firm's profit depends on the effort of the worker:

$$
\pi=q(e)-w(e)
$$

Profit is the difference between the value of the output generated by the effort of the worker, $q(e)$, and the wage cost. The production function has decreasing returns to worker's effort, $q^{\prime}(e)>0$ and $q^{\prime \prime}(e)<0$.

In this section, we assume that the firm observes the worker's motivation $\gamma$ and has all the bargaining power. The firm sets wage cost as low as possible, but the wage must meet the worker's participation constraint:

$$
U\left[w(e), e, \gamma_{i} e\right] \geq U^{\text {out }} \equiv U(b, 0,0)
$$

where $U^{\text {out }}$ is the outside option of the worker. We assume that the worker's alternative to employment at this firm is living on an unemployment benefit $b$. More generally, the outside option of the worker would take into account expected job opportunities at other firms. If other firms would offer jobs with the same kind of intrinsic qualities, a worker's outside option would depend on his motivation. This would weaken our argument that motivated workers are willing to work for a lower wage. In a related paper, we analyse the effects of competition in the labour market for intrinsically motivated workers (Delfgaauw and Dur, 2002). There, we show that competition leads to higher wages, stronger incentives, and higher productivity. In this paper, 
we abstract from outside job opportunities. We thus focus on situations where the firm has (sufficient) monopsonistic power, either because workers' intrinsic motivation is firm-specific or because there are no other firms (in the neighbourhood) offering jobs with the same intrinsic qualities.

The worker's optimal amount of effort is found by maximising the utility function (1) to $e$ :

$$
\max U \rightarrow w^{\prime}(e) U_{1}(\cdot)+U_{2}(\cdot)+\gamma_{i} U_{3}(\cdot)=0
$$

In the optimum, the worker's (financial and motivational) marginal benefits of effort equal the marginal cost of effort.

The firm maximises profits. Since the firm has all the bargaining power, it sets the worker's total compensation such that it leaves no rents to the worker. Though the firm does not directly control the worker's effort $e$, it can design a monetary incentive scheme that induces the worker to exert the optimal level of effort: ${ }^{6}$

$$
\max \pi \text { s.t. } U(\cdot) \geq U^{\text {out }} \rightarrow q^{\prime}(e)-w^{\prime}(e)=0
$$

In the optimum, the marginal product equals marginal wage cost.

First-order conditions (4) and (5) imply that if the firm sets the wage scheme optimally, the worker's marginal utility of effort, apart from the effect of extra effort on his income, is negative. Hence, people stating that they enjoy every aspect of their work ("my work is my hobby") are simply exerting too little effort (or, in other words, their wage scheme is suboptimal). Note also that (4) and (5) imply that monetary incentives are stronger, the less motivated is the worker (i.e., $w^{\prime}(e)$ is larger, the lower $\left.\gamma_{i}\right)$. Important for this result is our assumption that $q^{\prime \prime}(e)<0$. With constant returns to effort $\left[q^{\prime \prime}(e)=0\right]$, the optimal reward per unit of effort $w^{\prime}(e)$ equals the marginal product of effort $q^{\prime}(e)$, which is constant when $q^{\prime \prime}(e)=0$.

The firm sets total compensation to the worker such that it leaves no rents to the worker. In the optimum, the firm creates a compensation scheme which induces the worker to choose the level of effort defined by (4) and (5) at the lowest cost to the firm, implying that the worker ends up with a total utility of $U=U^{\text {out }}$, defined by (3).

Intrinsic motivation has two important effects. First, the higher $\gamma$, the higher the maximum wage the firm is willing to offer. Stated differently, given the level of the wage, it is more profitable to the firm to hire a worker who is more motivated. The maximum wage the firm is willing to offer is the wage which would leave the firm with zero profit:

$$
w(e)=q(e)
$$

\footnotetext{
${ }^{6}$ When neither effort nor production is verifiable, the firm cannot induce workers to provide optimal effort. We deal with this case at the end of this section.
} 
Since marginal productivity $q^{\prime}(e)$ is positive, we have to show that $e$ increases in $\gamma$. Applying the implicit function theorem to (4) results in:

$$
\frac{d e}{d \gamma}=\frac{U_{3}(\cdot)+e \gamma U_{33}(\cdot)}{-\partial^{2} U(\cdot) / \partial e^{2}}
$$

where $\partial^{2} U(\cdot) / \partial e^{2}<0$ is the second-order condition to the worker's optimisation problem (4). Effort increases in a worker's motivation if $U_{3}>-e \gamma U_{33}$. We assume that this condition holds: it is unlikely that a more motivated worker works less hard because he enjoys working already so much. More effort implies more output. Hence, the maximum wage the firm is willing to offer increases in the worker's motivation.

Second, given the level of effort, intrinsic motivation affects the wage the firm needs to offer to meet the worker's participation constraint. We show that for constant $e=\hat{e}$, the minimum wage for which the worker is willing to work decreases in $\gamma$. Applying the implicit function theorem to (3) results in:

$$
\frac{d w(\hat{e})}{d \gamma}=-\frac{\hat{e} U_{3}(\cdot)}{U_{1}(\cdot)}<0
$$

The expression in (8) is always negative: Given the level of effort, a worker who is more motivated for the job needs to be compensated less.

In general, the effect of motivation on total wage compensation is ambiguous. A more motivated worker needs to be compensated less for each unit of effort. However, he exerts more effort than less motivated workers, implying that the total wage may be increasing in motivation. In appendix 1 we prove that $\frac{d w(e)}{d \gamma}<0$ if the following condition holds:

$$
e U_{3}(\cdot)>-\left[U_{2}(\cdot)+\gamma_{i} U_{3}(\cdot)\right] \frac{d e}{d \gamma}
$$

The right-hand side of this inequality denotes the net increase in disutility due to the higher level of effort. The left-hand side is the increase in motivational utility derived from all effort the worker exerts, because of the higher motivation. If, in the new optimum, the increased pleasure of working is higher than the burden of the additional effort, highly motivated workers need less financial compensation than less motivated workers.

Higher motivation thus has two effects: the firm is willing to offer a higher wage, while, given the level of effort, the worker is willing to accept a lower wage. Motivation therefore increases the joint surplus of the worker and the firm. When the firm has all the bargaining power, it can extract all rents from the motivation of the worker by adjusting the compensation scheme. This implies that, if condition (9) is satisfied, more motivated workers will be offered lower wages, even though they are more productive. ${ }^{7}$ Hence,

\footnotetext{
${ }^{7}$ Allowing for a more equal distribution of bargaining power between the firm and the
} 
without a commitment of the firm not to extract all motivational rents, job applicants may be reluctant to reveal their motivation to the firm, or worse even, the firm may not be able to attract any applicant at all. Section 4 addresses this problem.

Both effects of intrinsic motivation are also present in the case of a fixed wage. When the firm is unable or unwilling to use incentive wages, ${ }^{8}$ the optimal level of effort of the worker is given by (4) with $w^{\prime}(e)$ equal to zero. The effect of intrinsic motivation on effort is still given by (7). Effort and thus output increase in the worker's motivation. This is also clear from Figure 1: a worker's optimal effort with a fixed wage is given by the top of the curve, which moves to the right, the higher is $\gamma$. Hence, the maximum fixed wage the firm is willing to offer increases in the worker's motivation. Moreover, the minimum fixed wage a worker is willing to accept decreases in motivation. By using first-order condition (4), we can rewrite condition (9) to:

$$
e U_{3}(\cdot)>w^{\prime}(e) U_{1}(\cdot) \frac{d e}{d \gamma}
$$

In case of a fixed wage, $w^{\prime}(e)=0$, condition (10) always holds. Therefore, the higher motivation, the higher the direct utility from effort, and the lower the wage needs to be in order to meet the participation constraint of the worker.

\section{Attracting and Selecting Motivated Workers}

This section examines how a firm can attract and select highly motivated workers to fill a vacancy. We consider three cases: One where the firm can observe the motivation of the applicants, one where it can not, and one where workers decide whether or not to signal their motivation. To focus on the distributional conflict between the firm and the worker, we abstract from monetary incentives and assume that the firm offers a base salary only. Allowing for monetary incentives does not affect the results qualitatively, which we show in Section 5, but it distracts attention from our main results.

workers need not affect this result. As long as the firm has sufficient bargaining power, the wage of the worker decreases in motivation, provided that condition (9) holds. See Appendix 2.

${ }^{8}$ One reason why firms may refrain from providing monetary incentives to motivated workers is high monitoring cost, see Weiss (1990, pp. 73-76). In case of multiple tasks, monetary incentives may crowd out facets of tasks which are hard to observe by facets of tasks which are more easily observed (Holmström and Milgrom, 1991). Alternatively, monetary incentives may crowd out intrinsic motivation, see Frey (1997a) and Benabou and Tirole. 


\subsection{Setup of the Model}

A firm has one vacancy, and posts a 'help-wanted' ad. As in the previous section, the firm has all the bargaining power. However, we assume that the firm can credibly commit to pay at least a certain wage by posting a base salary $w_{\min }$ in the ad. Workers differ in their intrinsic motivation $\gamma \in[0, \bar{\gamma}]$ to work at this firm, while their outside options are identical, $U^{\text {out }}$. There is a discrete number of worker types in the economy, with $n_{\gamma_{i}}$ workers of type $\gamma_{i}$. Denote by $N_{\gamma_{i}}$ the total number of workers with motivation equal to or higher than $\gamma_{i}$ :

$$
N_{\gamma_{i}}=\sum_{\gamma \geq \gamma_{i}} n_{\gamma}
$$

Each worker has probability $\mu$ of observing the ad, $0<\mu<1$. One reason for $\mu<1$ could be that not all workers read the newspaper every day. As a result, the firm is uncertain about the composition of the group of potential applicants. If a worker decides to apply, she incurs application cost $C .{ }^{9}$

Following the results from the previous section, worker $i$ 's indirect utility function can be written as $U\left(\gamma_{i}, w\right)$, with properties $U_{\gamma}(\cdot)>0$ and $U_{w}(\cdot)>0$, and profits of the firm as $\pi\left(\gamma_{i}, w\right)$, with properties $\pi_{\gamma}(\cdot)>0$ and $\pi_{w}(\cdot)<0$. Since condition (9) is always satisfied in case of a fixed wage, the minimum wage offer a worker is willing to accept decreases in motivation. That is, if $\gamma>\gamma^{\prime}$, then $U(\gamma, w)=U\left(\gamma^{\prime}, w^{\prime}\right)$ implies that $w<w^{\prime}$.

\subsection{Observable Motivation}

Suppose the firm can observe the level of intrinsic motivation of each applicant during the selection process. The sequence of events is as follows:

1. The firm posts a 'help-wanted' ad, in which it can credibly commit to a minimum wage.

2. The workers who observe the ad decide whether or not to apply. If a worker applies, she incurs cost $C$.

3. The firm observes the types of all applicants, selects one applicant, and makes her a wage offer $w$.

4. The applicant accepts or rejects. Rejection results in zero profits. ${ }^{10}$

\footnotetext{
${ }^{9}$ Instead of $\mu<1$, we could also assume that $C$ is a random variable which differs among workers. Important for the results is that the firm faces some uncertainty about the composition of the group of applicants.

${ }^{10} \mathrm{~A}$ more general set-up of the game would allow the firm to make a wage offer to another applicant (or a better wage offer to the same worker) after a rejection. While this could reduce the probability to end up with an unfilled vacancy, it may increase the rents that have to be left to the hired worker. Workers may wait for a next (higher) wage offer at the risk that an other applicant accepts one of the firm's next offers. Allowing for multiple wage offers will also affect the decision to apply. We leave this for future research.
} 
We first consider the case where the firm has not committed to a minimum wage at stage 1 . We solve the model by backward induction. The optimal strategy of each worker at stage 4 is simple: Accept if and only if $U\left(\gamma_{i}, w\right) \geq U^{\text {out }}$. Application costs are sunk at this stage. As profits increase in the worker's motivation, the firm optimally selects the most motivated worker among the applicants. The optimal wage offer is such that $U(\gamma, w)=U^{\text {out }}$. This strategy of the firm at stage 3 makes that no worker applies at stage 2. Each worker anticipates that the firm extracts all rents of her motivation, leaving the worker with the sunk application cost. ${ }^{11}$ This result is known as the Diamond paradox (Diamond; see also Mortensen and Pissarides, 1999). ${ }^{12}$

To give workers an incentive to apply, the firm must make a credible commitment not to extract all rents from their motivation. It can do so by putting a minimum wage $w_{\min }$ in the ad at stage $1 .{ }^{13}$ If the minimum wage is sufficiently high, some worker types have positive expected benefits from applying. Since $\pi_{\gamma}(\cdot)>0$, the firm still selects the most motivated worker from the pool of applicants at stage 3 . If the lowest wage that this worker would accept is below the minimum wage, the minimum wage is binding. Otherwise, the firm offers the wage that makes the worker indifferent between accepting and rejecting. However, as above, these workers optimally do not apply. Hence, the firm always offers $w_{\min }$.

At stage 2, worker $i$ applies if the expected benefits from applying are positive. Obviously, if a certain worker type has positive expected benefits from applying, all workers with higher motivation also have positive expected benefits from applying. A worker of type $\gamma_{i}$ applies if and only if:

$$
f\left(\gamma_{i}\right)\left[U\left(\gamma_{i}, w_{\min }\right)-U^{\text {out }}\right]-C \geq 0
$$

where $f\left(\gamma_{i}\right)$ is the expected probability for a worker of type $\gamma_{i}$ of being selected by the firm and $U\left(\gamma_{i}, w_{\min }\right)$ is the utility that the worker obtains if she accepts offer $w_{\min } . f\left(\gamma_{i}\right)$ is determined by the distribution of worker types:

$$
f\left(\gamma_{i}\right)=(1-\mu)^{N_{\gamma_{i}}-n_{\gamma_{i}}} \sum_{x=0}^{n_{\gamma_{i}}-1}\left[\frac{1}{1+x}\left(\begin{array}{c}
n_{\gamma_{i}}-1 \\
x
\end{array}\right) \mu^{x}(1-\mu)^{n_{\gamma_{i}}-1-x}\right]
$$

where $N_{\gamma_{i}}$ is given by (11). The first term is the probability that all workers with $\gamma>\gamma_{i}$ do not observe the ad. If any of these workers applies, then

\footnotetext{
${ }^{11}$ The assumption that the firm makes a take-it-or-leave-it wage offer implies that even if there is a single most motivated worker, $n_{\bar{\gamma}}=1$, this worker can not capture any rents.

${ }^{12}$ Note that if $C=0$, all workers who observe the ad apply. The firm selects the most motivated worker and offers her the wage that exactly meets her participation constraint, as described in Section 3.

${ }^{13}$ We assume that posting a range of wage offers conditional on a worker's motivation is not credible, due to the unverifiability of the level of motivation. Thus, posting a single wage is the best the firm can do.
} 
worker $i$ will not be selected by the firm. The second term gives the probability that worker $i$ is selected from all applicants of the same type. This probability is the function $\frac{1}{1+x}$, where $x$ is the number of applicants with motivation $\gamma_{i}$ besides worker $i$, which follows a binomial distribution.

The firm sets the minimum wage such that expression (12) holds with equality for the least motivated worker type that it wants to apply. Denote this worker type by $\gamma_{\min }$. As argued above, if $w_{\min }<w_{\min }^{\prime}$, then $\gamma_{\min }>$ $\gamma_{\min }^{\prime}$. Expected profits are given by:

$$
E\left[\pi\left(\gamma, w_{\min }\right)\right]=\sum_{\gamma \geq \gamma_{\min }} F(\gamma) \pi\left(\gamma, w_{\min }\right)
$$

where

$$
F(\gamma)=(1-\mu)^{N_{\gamma}-n_{\gamma}}\left[1-(1-\mu)^{n_{\gamma}}\right]
$$

is the probability that $\gamma$ is the highest level of motivation among the applicants, and $\pi\left(\gamma, w_{\min }\right)$ is the accompanying level of profit. Suppose the firm increases the minimum wage from $w_{\min }$ to $w_{\min }^{\prime}$ such that $\gamma_{\min }$ decreases by one worker type to $\gamma_{\text {min }}^{\prime}$. This leads to the following change in expected profits:

$$
\begin{aligned}
\Delta E[\pi] & =E\left[\pi\left(\gamma, w_{\min }^{\prime}\right)\right]-E\left[\pi\left(\gamma, w_{\min }\right)\right] \\
& =\sum_{\gamma \geq \gamma_{\min }^{\prime}} F(\gamma) \pi\left(\gamma, w_{\min }^{\prime}\right)-\sum_{\gamma \geq \gamma_{\min }} F(\gamma) \pi\left(\gamma, w_{\min }\right)
\end{aligned}
$$

which can be written as:

$$
\Delta E[\pi]=F\left(\gamma_{\min }^{\prime}\right) \pi\left(\gamma_{\min }^{\prime}, w_{\min }^{\prime}\right)+\sum_{\gamma \geq \gamma_{\min }} F(\gamma)\left[\pi\left(\gamma, w_{\min }^{\prime}\right)-\pi\left(\gamma, w_{\min }\right)\right]
$$

Increasing the minimum wage leads to a higher probability of filling the vacancy, as an additional worker type, $\gamma_{\text {min }}^{\prime}$, has an incentive to apply after observing the ad. This is reflected by the first term. However, if some worker with motivation higher than $\gamma_{\min }^{\prime}$ observes the vacancy, the increase in the minimum wage only leads to additional cost, as this worker would have applied at the lower minimum wage as well. This is described by the second term.

The firm sets the minimum wage such that $0 \leq \gamma_{\min } \leq \bar{\gamma}$. A local optimum of $E\left[\pi\left(\gamma, w_{\min }\right)\right]$ can be found by stepwise increasing the minimum wage until the sign of $\Delta E[\pi]$ turns negative. Whether there is only one local (and thus global) optimum is unsure given the general specification of the distribution of worker types and of the profit function $\pi\left(\gamma, w_{\min }\right)$. More specifically, if, for a value of $w_{\min }$ above the local optimum, a small increase in $w_{\min }$ results in a large increase in the probability of filling the vacancy, then $E\left[\pi\left(\gamma, w_{\min }\right)\right]$ may not be concave in $w_{\min }$, and, hence, there may be 
more than one local optimum. Restricting the distribution of worker types such that $n_{\gamma}=n$ for all $\gamma$ and $\pi\left(\gamma, w_{\min }^{\prime}\right)-\pi\left(\gamma, w_{\min }\right)$ is constant in $w_{\min }$ (that is, the increase in $w_{\text {min }}$ necessary to attract one additional worker type is equal for all worker types), both terms of (16) decrease with $w_{\min }$. This implies that $E\left[\pi\left(\gamma, w_{\min }\right)\right]$ is concave in $w_{\min }$ and, hence, there exists only one local and global optimum. Corner solutions cannot be excluded: It is possible that the optimal $\gamma_{\min }$ is either 0 or $\bar{\gamma}$.

\subsection{Unobservable Motivation}

When the firm can not observe the types of the applicants, it randomly selects one applicant and makes her a wage offer. As in the previous subsection, we assume that when the wage offer is rejected, the firm ends up with zero profits.

Consider first the case where the firm has not committed to a minimum wage. The beliefs of the firm about the distribution of applicants' types are crucial in determining the optimal wage offer. Suppose that the firm believes that there exists some $\gamma_{l}$ such that only workers with $\gamma_{i} \geq \gamma_{l}$ apply after observing the vacancy. Let $w_{l}$ be the wage such that $U\left(\gamma_{l}, w_{l}\right)=U^{\text {out }}$. Given the firm's beliefs, its optimal wage offer $w$ is such that $w_{\bar{\gamma}} \leq w \leq w_{l}$. Hence, workers of type $\gamma_{l}$ optimally decide not to apply as the wage offer does not compensate them for the application cost. This, in turn, reduces the firm's optimal wage, which removes the incentives of workers with slightly higher motivation to apply. As this holds for any $\gamma_{l}$ (including $\bar{\gamma}$ ), the market collapses, as in Akerlof's lemon market. In Akerlof's model, the existence of bad types drives the good types out of the market. Interestingly, in our model, it is the withdrawal of the bad types from the market that drives out the good types.

Again, the firm needs to commit to a minimum wage in order to attract applicants. In Appendix 3, we derive the optimal minimum wage when workers' motivation is unobservable. Compared to the case where motivation is observable, there is an additional selection effect of raising the wage. As before, a higher minimum wage induces workers who are less motivated to apply. Hence, the average level of intrinsic motivation of applicants goes down. If the firm can fully observe applicants' motivation, this reduction in average motivation of applicants does not entail a cost since the firm simply chooses the best motivated worker among the applicants. However, if applicants' motivation is unobservable, the firm picks an applicant randomly, and, hence, higher wages reduce the expected level of motivation of the worker that is hired. The selection effect imposes an additional cost of increasing the minimum wage compared to the case where motivation is observable, and so the optimal minimum wage is lower. ${ }^{14}$

\footnotetext{
${ }^{14}$ If $C=0$, the firm need not to commit to a minimum wage to attract applicants. However, the selection effect makes that the firm might want to commit to a maximum
} 


\subsection{Motivation Can Be Signaled}

Suppose that the firm can not observe the motivation of the applicants, but applicants can credibly signal their type to the firm. ${ }^{15}$ Obviously, when the firm does not commit to a minimum wage, none of the workers apply, as in the previous subsections. Each applicant anticipates that when she signals her type, the firm fully extracts all the rents of motivation, leaving the applicant with the sunk application cost. Because no applicant reveals her type to the firm, motivation remains unobservable. As we have seen in the previous subsection, this results in a complete breakdown of the market.

When the firm posts a minimum wage $w_{\min }$, each applicant signals her motivation to the firm. The intuition is that signaling increases a worker's probability of getting the job. Consider an applicant with motivation $\bar{\gamma}$ and suppose that all other applicants do not signal their motivation. If she signals, she is certain to get the job. If she does not signal, she only gets the job if she is randomly selected. Hence, she signals her type as signaling increases her probability of being selected by the firm. This also holds when other workers signal. Next, consider workers of the highest but one type of motivation, $\gamma_{h}$. Signaling is of no avail when a worker of type $\bar{\gamma}$ is in the pool of applicants. However, if none of the workers of type $\bar{\gamma}$ apply, signaling is beneficial, as the firm prefers to select a worker of type $\gamma_{h}$ if there are no workers of type $\bar{\gamma}$ available. Since workers have no information about the other applicants and signaling is costless, it is always in the interest of workers of type $\gamma_{h}$ to signal their type. Analogously, all applicants have an incentive to signal their type so as to increase the probability of getting the job.

It follows that a worker only gets the job if she is the most motivated applicant, as in Subsection 4.1 where the firm could observe the motivation of the applicants. Hence, workers have the same incentives to apply as in Subsection 4.1, and the firm optimally sets the minimum wage at the same level.

\section{Signaling and Screening with Optimal Monetary Incentive Schemes}

This section shows that the results derived in Section 4 under the assumption of a fixed wage generalise to the case where the firm provides monetary incentives to the worker, as in Section 3.

wage, in order to reduce the number of relatively less motivated workers in the pool of applicants, as in Handy and Katz. Note also that a maximum wage is of no use when $C>0$.

${ }^{15}$ If signals are not credible, motivation remains unobservable, as all applicants would signal that they have motivation $\bar{\gamma}$. 


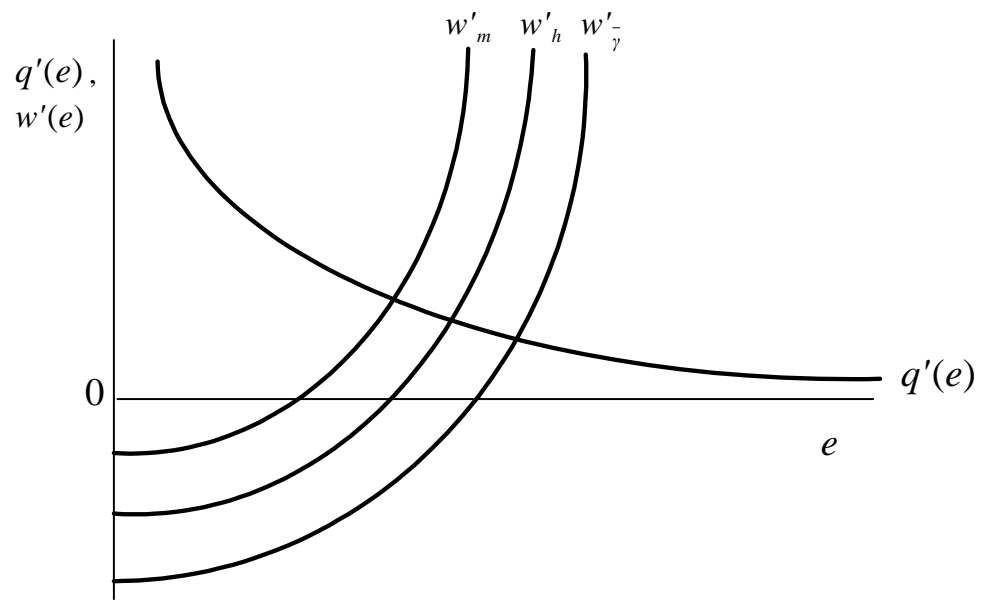

Figure 2: Intrinsic motivation and the optimal monetary incentive scheme

Suppose the firm wants that only workers with motivation $\bar{\gamma}$ apply. Analogous to the previous section, the firm needs to commit to a minimum wage scheme in order to attract applicants, regardless of whether or not the firm can observe the motivation of the applicants. The firm has to commit to a minimum wage scheme that satisfies the following constraint:

$$
p(\bar{\gamma})\left\{U[w(e), e, \bar{\gamma} e]-U^{\text {out }}\right\}-C \geq 0
$$

where $p(\bar{\gamma})$ is the probability of getting the job for a worker of type $\bar{\gamma}$, given by (13) in case of observable motivation and by (A8) in case of unobservable motivation, respectively. Optimal effort is again described by first-order conditions (4) and (5), with $\gamma_{i}=\bar{\gamma}$. Clearly, there exist many wage schemes that satisfy these conditions. One of these is depicted in Figure 2.

Figure 2 depicts the marginal product of effort $\left[q^{\prime}(e)\right]$ and the marginal disutility from effort for three different types of workers. The latter curves are obtained by rewriting the first-order condition for optimal effort of the worker (4) to:

$$
w_{i}^{\prime}(e)=-\frac{U_{2}(\cdot)+\gamma_{i} U_{3}(\cdot)}{U_{1}(\cdot)}
$$

where $i \in\{m, h, \bar{\gamma}\}, \gamma_{m}<\gamma_{h}<\bar{\gamma}$. Equation (17) describes for each level of effort the minimum reward the firm must provide to induce a worker of type $\gamma_{i}$ to provide an additional unit of effort. Notice that when the firm creates an incentive scheme which follows (17) exactly, the worker is just compensated for his (net) disutility from effort. In order to give workers an incentive to apply, the firm has to make sure that a worker with motivation $\gamma_{\text {min }}=\bar{\gamma}$ ends up (in expected terms) with utility $U^{\text {out }}$. Hence, the firm 
must offer a base salary $B_{\gamma_{\min }}$ such that:

$$
U\left(B_{\gamma_{\min }}, 0,0\right)=U^{\text {out }}+\frac{C}{p\left(\gamma_{\min }\right)}
$$

An optimal minimum wage scheme which induces only workers with motivation $\bar{\gamma}$ to apply thus consists of a base salary $B_{\gamma_{\min }}$, given by (18) with $\gamma_{\min }=\bar{\gamma}$, and a monetary incentive scheme which follows (17) up to the point where $w_{\bar{\gamma}}^{\prime}(e)=q^{\prime}(e)$. Denote the accompanying level of effort by $e_{\bar{\gamma}}$. The firm's offer is:

$$
B_{\bar{\gamma}}+\int_{0}^{e_{\bar{\gamma}}} w_{\bar{\gamma}}^{\prime}(e) d e
$$

This minimum wage offer is just sufficient to induce workers with motivation $\bar{\gamma}$ to apply. All other worker types have negative expected benefits from applying, and, hence, decide not to apply.

Now suppose the firm prefers to give the highest two types an incentive to apply, types $\bar{\gamma}$ and $\gamma_{h}$. As in the previous section, this implies that the firm has to leave a rent to workers of type $\bar{\gamma}$. The firm optimally trades off the rents it has to leave in case the selected applicant appears to be a worker of type $\bar{\gamma}$ and the effort exerted by a worker of type $\gamma_{h}$. The profit maximising wage scheme which is acceptable to both types of workers is described by:

$$
\max _{e_{h}} P\left(\gamma_{h}\right)\left[q\left(e_{h}\right)-B_{\gamma_{h}}-w_{h}\left(e_{h}\right)\right]+P(\bar{\gamma})\left[q\left(e_{\bar{\gamma}}\right)-B_{\gamma_{h}}-w_{h}\left(e_{h}\right)-\int_{e_{h}}^{e_{\bar{\gamma}}} w_{\bar{\gamma}}^{\prime}(e) d e\right]
$$

where $e_{h}$ is the level of effort a worker of type $\gamma_{h}$ is induced to exert by this profit maximising scheme, and $P\left(\gamma_{h}\right)$ and $P(\bar{\gamma})$ are the probabilities that a worker of type $\gamma_{h}$ and a worker of type $\bar{\gamma}$ are hired, given by (15) when motivation is observable and by (A10) when motivation is unobservable, respectively. Base salary $B_{\gamma_{h}}$ is implicitly given by (18) with $\gamma_{\min }=\gamma_{h}$, and $w_{h}(\cdot)$ and $w_{\bar{\gamma}}^{\prime}(\cdot)$ are described by (17) with $\gamma_{i}=\gamma_{h}, \bar{\gamma}$, respectively. The first term in brackets is the firm's profit in case a worker of type $\gamma_{h}$ is hired, which happens with probability $P\left(\gamma_{h}\right)$. In expected terms, the firm does not leave a rent to these workers. The first derivative with respect to $e_{h}$ of this term is equal to zero when $e_{h}$ equals the optimal effort level of workers of type $\gamma_{h}$ under full information, described in Section 3. The second term in brackets is the firm's profit in case a worker of type $\bar{\gamma}$ is hired, which happens with probability $P(\bar{\gamma})$. To meet this worker's individual rationality constraint, the firm must provide monetary incentives as if the worker is of type $\gamma_{h}$ up to effort level $e_{h}$. Hence, the firm leaves a rent to workers of type $\bar{\gamma}$. Starting from effort level $e_{h}$, the firm just compensates workers of type $\bar{\gamma}$ for each additional unit of effort. The first derivative with respect to $e_{h}$ of the second term is always negative since $w_{h}^{\prime}(e)>w_{\bar{\gamma}}^{\prime}(e)$ for any e. Clearly, 
it is in the firm's interest to set $e_{h}$ lower than the optimal effort level under full information, which we derived in Section 3. The profit maximising wage scheme induces a worker of type $\gamma_{h}$ to exert suboptimally low effort so as to reduce the rents which the firm has to leave in case the offer is made to a worker of type $\bar{\gamma} \cdot{ }^{16}$ Workers of type $\bar{\gamma}$ are induced to exert an efficient level of effort, as in Section 3. The firm must, however, leave a rent to these workers. The optimal wage scheme which gives types $\bar{\gamma}$ and $\gamma_{h}$ an incentive to apply is described by:

$$
B_{\gamma_{h}}+\int_{0}^{e_{h}} w_{h}^{\prime}(e) d e+\int_{e_{h}}^{e_{\bar{\gamma}}} w_{\bar{\gamma}}^{\prime}(e) d e
$$

Along the same lines, we can derive the optimal wage scheme when the firm wants to induce more worker types to apply. The lower $\gamma_{\min }$, the higher the base salary and the higher the incentive wage up to $e_{\gamma_{\min }}$ must be in order to give workers with motivation $\gamma \geq \gamma_{\min }$ an incentive to apply. The wage scheme is such that each worker type - except $\bar{\gamma}-$ exerts a suboptimal level of effort, so as to decrease the rents the firm has to leave to higher types. As in Section 4, the optimal wage scheme entails a trade-off between the probability of filling the vacancy, the rents left to workers, and, if motivation is unobservable, the expected quality of the selected worker. It is straightforward to show that the firm needs to commit to a sufficiently high base salary so as to attract applicants and to give them an incentive to signal their motivation.

\section{Concluding remarks}

This paper has studied a firm's optimal recruitment, selection, and pay-forperformance practices when workers differ in their intrinsic motivation to work at the firm. We have shown that, when intrinsic motivation can not be observed by the firm, posting a higher wage may increase the probability of filling a vacancy, but at the same time decrease the expected motivation of the hired worker. Screening technologies, like personality and workstyle tests, work trials, and the use of assessment centres, may help a firm to select the best motivated worker among the applicants. But these may only help if the firm commits to pay at least a certain wage. For otherwise, workers may have an incentive to conceal their motivation or, even worse, to abstain from applying.

Our model predicts that when workers' motivation is more easy to assess, workers' productivity and wages will be higher. Productivity is higher since the firm is better able to select the best-motivated applicant. Wages will also

\footnotetext{
${ }^{16}$ For a similar result in a more general context see chapter 7 in Fudenberg and Tirole (1992).
} 
be higher as there is less need to discourage low-motivated worker from applying by offering a low wage. When workers' employment history contains some information on workers' motivation, older workers' motivation may be more easy to asses than younger workers' motivation. Adverse selection problems arising from heterogeneity in workers' motivation may therefore increase the wage premium on labour market experience. A testable implication of our model therefore is that in sectors where workers' intrinsic motivation is important, wage-experience profiles are steeper.

Heterogeneity in workers' motivation may also affect the effects of intensifying competition in an industry. In a related paper, we extend our model to examine the consequences of creating a fully competitive market in a sector previously dominated by a monopsonistic firm (Delfgaauw and Dur). We show that firms in a competitive market provide stronger monetary incentives to workers, pay higher wages, and employ less workers than a monopsonistic firm. These findings square well with the empirical evidence on the effects of privatisation and liberalisation.

We have adopted a very simple concept of workers' intrinsic motivation, namely that workers to a certain extent enjoy exerting effort at work. We have assumed that this enjoyment of effort is independent of the firm's pay policies. Adopting a more sophisticated concept of intrinsic motivation may reveal interesting additional effects to the ones we discussed above. For instance, a higher wage may change the public perception of how noble a task or job is, which in turn may reduce workers' motivation to do the job. Seabright (2002) and Janssen and Mendys-Kamphorst (2004) have recently developed models along these lines. Moreover, offering pay-for-performance may undermine workers' intrinsic motivation as they feel that their intrinsic motivation is not acknowledged by the firm (see Frey, 1997a, and Frey and Jegen, 2001).

\section{Acknowledgements}

We would like to express our gratitude to two anonymous referees for providing many valuable suggestions and comments. We also thank Bruno Frey, Pieter Gautier, Otto Swank, Harry Verbon, participants of the 2002 Annual Meeting of the European Public Choice Society, and seminar participants in Rotterdam for useful comments on earlier drafts. We gratefully acknowledge financial support from NWO, KNAW and VSNU through a Vernieuwingsimpuls grant.

\section{A Appendix 1}

In this appendix we derive the condition under which the total wage compensation decreases in motivation. For this purpose, it is convenient to write the wage scheme as:

$$
w(e)=q(e)+B
$$


Hence, in line with first-order condition (5), workers get their full marginal product, while the base salary $B$ is such that the participation constraint of the worker is just satisfied:

$$
U(w(e), e, \gamma e)=U(q(e)+B, e, \gamma e)=U^{o u t}
$$

By combining the optimal wage scheme (A1) and the first-order conditions for effort (4) and profit (5), it follows that the optimal level of effort is implicitly given by:

$$
q^{\prime}(e) U_{1}(\cdot)+U_{2}(\cdot)+\gamma U_{3}(\cdot)=0
$$

In Section 3, we derived the effect of a marginal change in $\gamma$ on the optimal level of effort:

$$
\frac{d e}{d \gamma}=\frac{U_{3}(\cdot)+e \gamma U_{33}(\cdot)}{-\partial F / \partial e}>0
$$

where $\partial F / \partial e<0$ is the second-order condition to the worker's optimisation problem (A3). We are interested in the sign of $\frac{d w(e)}{d \gamma}$. By using (A1), we can rewrite this to:

$$
\frac{d w(e)}{d \gamma}=\frac{d q(e)}{d \gamma}+\frac{d B}{d \gamma}
$$

The first term on the right-hand side of this equation is simply:

$$
\frac{d q(e)}{d \gamma}=q^{\prime}(e) \frac{d e}{d \gamma}
$$

where $\frac{d e}{d \gamma}$ is given by (A4). The second term on the right-hand side of (A5) can be found by using the participation constraint (A2) and applying the implicit function theorem:

$$
\frac{d B}{d \gamma}=-\frac{e U_{3}}{U_{1}}+\frac{\left[q^{\prime}(e) U_{1}(\cdot)+U_{2}(\cdot)+\gamma U_{3}(\cdot)\right]}{U_{1}(\cdot)} \frac{d e}{d \gamma}=-\frac{e U_{3}}{U_{1}}
$$

where the term in square brackets is zero by first-order condition (A3) (the envelop theorem). Hence, we can rewrite (A5) as:

$$
\frac{d w(e)}{d \gamma}=q^{\prime}(e) \frac{d e}{d \gamma}-\frac{e U_{3}(\cdot)}{U_{1}(\cdot)}=\frac{-\left[U_{2}(\cdot)+\gamma U_{3}(\cdot)\right] \frac{d e}{d \gamma}-e U_{3}(\cdot)}{U_{1}(\cdot)}
$$

where the second equality follows from (A3). Total wage compensation thus decreases in motivation if the following condition holds:

$$
e U_{3}(\cdot)>-\left[U_{2}(\cdot)+\gamma U_{3}(\cdot)\right] \frac{d e}{d \gamma}
$$

which is identical to condition (9) in the main text. 


\section{B Appendix 2}

Suppose the wage results from a bargain between the firm and the worker, of which the outcome is described by the generalised Nash bargaining function. The worker's bargaining power is denoted by $\chi$, the firm has bargaining power $1-\chi(0 \leq \chi \leq 1)$. Note that apart from the total compensation to the worker, the incentive scheme derived in Section 3 is optimal for both the firm and the worker. Denote the minimum wage for which the worker is willing to work by $w_{\min }(\gamma)$. The maximum wage the firm is willing to offer is denoted by $w_{\max }(\gamma)$. The wage that results from the bargaining is the minimum wage plus a proportion $\chi$ of the total rents (the difference between the maximum and the minimum wage):

$$
w=w_{\min }(\gamma)+\chi\left[w_{\max }(\gamma)-w_{\min }(\gamma)\right]
$$

To examine the effect of $\gamma$ on $w$, we differentiate this function with respect to $\gamma$ :

$$
\frac{d w}{d \gamma}=\chi w_{\max }^{\prime}(\gamma)+(1-\chi) w_{\min }^{\prime}(\gamma)
$$

In Section 3 we have shown that $w_{\max }^{\prime}(\gamma)>0$ and $w_{\min }^{\prime}(\gamma)<0$, provided that condition (9) holds. The wage decreases in motivation if:

$$
\frac{\chi}{\chi-1}<\frac{w_{\min }^{\prime}(\gamma)}{w_{\max }^{\prime}(\gamma)}
$$

Hence, as long as $\chi$ is sufficiently low, the wage decreases in the motivation of the worker.

\section{Appendix 3}

Suppose the firm puts minimum wage $w_{\min }$ in its ad. ${ }^{17}$ When motivation is unobservable a worker of type $\gamma_{i}$ applies if and only if:

$$
g\left(\gamma_{i}\right)\left[U\left(\gamma_{i}, w_{\min }\right)-U^{\text {out }}\right]-C \geq 0
$$

where $g\left(\gamma_{i}\right)$ is the expected probability for a worker with motivation $\gamma_{i}$ of being randomly selected by the firm after applying. This probability is $\frac{1}{1+v}$, where $v$ is the number of applicants besides worker $i . v$ is a random variable which follows a binomial distribution. It is easily verified that:

$$
g\left(\gamma_{i}\right)=\sum_{v=0}^{N_{\gamma_{i}}-1}\left[\frac{1}{1+v}\left(\begin{array}{c}
N_{\gamma_{i}}-1 \\
v
\end{array}\right) \mu^{v}(1-\mu)^{N_{\gamma^{i}}-1-v}\right]
$$

\footnotetext{
${ }^{17}$ Clearly, this will also be the firm's actual offer. Offering a wage which is higher than the wage announced in the ad could only be optimal if the firm believed that the least motivated applicants would reject offer $w_{\min }$. However, these workers anticipate that they will not be compensated for the application cost and, hence, optimally decide not to apply. As in the absence of a commitment, the firm's beliefs are unsustainable.
} 
The firm sets the minimum wage such that expression (A7) holds with equality for the least motivated worker type, $\gamma_{\min }$, that it wants to apply. Expected profits of the firm are given by:

$$
E\left[\pi\left(\gamma, w_{\min }\right)\right]=\sum_{\gamma \geq \gamma_{\min }} G(\gamma) \pi\left(\gamma, w_{\min }\right)
$$

where $G(\gamma)$ is the probability that the firm selects an applicant with motivation $\gamma$. This probability is $\frac{S}{S+Z}$, where $S$ is the number of applicants of type $\gamma$ and $Z$ the number of applicants with a different type of motivation. Both $S$ and $Z$ follow a binomial distribution, and their joint distribution is given by:

$$
\begin{aligned}
P(S=s, Z=z) & =P(S=s) P(Z=z) \\
& =\left(\begin{array}{c}
n_{\gamma} \\
s
\end{array}\right) \mu^{s}(1-\mu)^{n_{\gamma}-s}\left(\begin{array}{c}
N_{\gamma_{\min }}-n_{\gamma} \\
z
\end{array}\right) \mu^{z}(1-\mu)^{N_{\gamma_{\min }}-n_{\gamma}-z}
\end{aligned}
$$

where the first equality follows from the observation that the two random variables $S$ and $Z$ are independently distributed. Hence, $G(\gamma)$ is described by:

$G(\gamma)=\sum_{s=1}^{n_{\gamma}} \sum_{z=0}^{N_{\gamma_{\min }}-n_{\gamma}} \frac{s}{s+z}\left(\begin{array}{c}n_{\gamma} \\ s\end{array}\right) \mu^{s}(1-\mu)^{n_{\gamma}-s}\left(\begin{array}{c}N_{\gamma_{\min }}-n_{\gamma} \\ z\end{array}\right) \mu^{z}(1-\mu)^{N_{\gamma_{\min }}-n_{\gamma}-z}$

The summation over $s$ starts at $s=1$, because $G(\gamma)=0$ if none of the workers with motivation $\gamma$ observes the ad. Note that $\sum_{\gamma \geq \gamma_{\min }} G(\gamma)<$ 1 , as there may be no applicant at all, which happens with probability $(1-\mu)^{N_{\gamma_{\min }}}$.

Suppose the firm increases the minimum wage from $w_{\min }$ to $w_{\min }^{\prime}$, such that $\gamma_{\min }$ decreases by one worker type to $\gamma_{\min }^{\prime}$. This reduces the probability of selecting an applicant with motivation $\gamma$ to:

$G^{\prime}(\gamma)=\sum_{s=1}^{n_{\gamma}} \sum_{z=0}^{N_{\gamma_{\min }^{\prime}}-n_{\gamma}} \frac{s}{s+z}\left(\begin{array}{c}n_{\gamma} \\ s\end{array}\right) \mu^{s}(1-\mu)^{n_{\gamma}-s}\left(\begin{array}{c}N_{\gamma_{\min }^{\prime}}-n_{\gamma} \\ z\end{array}\right) \mu^{z}(1-\mu)^{N_{\gamma_{\min }^{\prime}}-n_{\gamma}-z}$

Since $N_{\gamma_{\min }^{\prime}}>N_{\gamma_{\min }}$ by definition, $G^{\prime}(\gamma)<G(\gamma)$ for all $\gamma \in\left[\gamma_{\min }, \bar{\gamma}\right]$. Intuitively, the probability that a worker of a certain type is selected decreases if the number of worker types that apply increases. This is the selection effect. As before, the increase in the minimum wage decreases the probability that nobody applies, as $\sum_{\gamma \geq \gamma_{\min }^{\prime}} G^{\prime}(\gamma)>\sum_{\gamma \geq \gamma_{\min }} G(\gamma)$.

The increase in the minimum wage from $w_{\min }$ to $w_{\min }^{\prime}$ leads to the following change in expected profits:

$$
\begin{aligned}
\Delta E[\pi] & =E\left[\pi\left(\gamma, w_{\min }^{\prime}\right)\right]-E\left[\pi\left(\gamma, w_{\min }\right)\right] \\
& =\sum_{\gamma \geq \gamma_{\min }^{\prime}} G^{\prime}(\gamma) \pi\left(\gamma, w_{\min }^{\prime}\right)-\sum_{\gamma \geq \gamma_{\min }} G(\gamma) \pi\left(\gamma, w_{\min }\right)
\end{aligned}
$$


which can be rewritten as:

$\Delta E[\pi]=G^{\prime}\left(\gamma_{\min }^{\prime}\right) \pi\left(\gamma_{\min }^{\prime}, w_{\min }^{\prime}\right)+\sum_{\gamma \geq \gamma_{\min }}\left[G^{\prime}(\gamma) \pi\left(\gamma, w_{\min }^{\prime}\right)-G(\gamma) \pi\left(\gamma, w_{\min }\right)\right]$

The first term gives the probability of selecting a worker with motivation $\gamma_{\min }^{\prime}$ and the accompanying profits. The second term indicates that by increasing $w_{\min }$ to $w_{\min }^{\prime}$, each worker type $\gamma \geq \gamma_{\min }$ has a lower probability of being selected, and, given a selected worker type, the profit of the firm is lower as a result of the wage increase. This expression is negative, since $G^{\prime}(\gamma)<G(\gamma)$ for all $\gamma \in\left[\gamma_{\min }, \bar{\gamma}\right]$ and $\pi\left(\gamma, w_{\min }^{\prime}\right)<\pi\left(\gamma, w_{\min }\right)$. As in Subsecion 4.2, the optimal minimum wage is found by stepwise increasing the minimum wage until the sign of $\Delta E[\pi]$ turns negative. See the last paragraph of Subsection 4.2.

\section{References}

[1] Akerlof, G.A., 1970. The market for 'lemons': quality, uncertainty, and the market mechanism. Quarterly Journal of Economics 84, 488-500.

[2] Akerlof, G.A., 1982. Labor contracts as partial gift exchange. Quarterly Journal of Economics 97, 543-569.

[3] Agell, J., Lundborg, P., 1999. Survey evidence on wage rigidity and unemployment: Sweden in the 1990s. Working Paper Series, Department of Economics, Uppsala University, No. 1999:12.

[4] Baron, J.N. 1988., The employment relation as a social relation. Journal of the Japanese and International Economies 2, 492-525.

[5] Bartram, D., Lindley, A.P., Marshall, L., Foster, Julie., 1995. The recruitment and selection of young people by small businesses. Journal of Occupational and Organizational Psychology 68, 339-358.

[6] Benabou, R., Tirole, J., 2003. Intrinsic and extrinsic motivation. Review of Economic Studies 70, 489-520.

[7] Besley, T., Ghatak, M., 2004. Competition and incentives with motivated agents. American Economic Review, forthcoming.

[8] Bewley, T.F., 1998. Why not cut pay? European Economic Review 42, 459-490.

[9] Brown, C., 1980. Equalizing differences in the labor market. Quarterly Journal of Economics 94, 113-134.

[10] Burdett, K., Shi, S., Wright, R., 2001. Pricing and matching with frictions. Journal of Political Economy 109, 1060-1085. 
[11] Cho, I.-K., Kreps, D.M., 1987. Signaling games and stable equilibria. Quarterly Journal of Economics 102, 179-222.

[12] DeCharms, R., 1968. Personal Causation: The Internal Effective Determinants of Behavior. Academic Press, New York.

[13] Deci, E.L., 1971. Effects of externally mediated rewards on intrinsic motivation. Journal of Personality and Social Psychology 18, 105-115.

[14] Delfgaauw, J., Dur, R., 2002. From public monopsony to competitive market: more efficiency but higher prices, Tinbergen Institute Discussion Paper 02-118/1.

[15] Diamond, P.A., 1971. A model of price adjustment. Journal of Economic Theory $3,156-168$.

[16] Dixit, A., 2002. Incentives and organizations in the public sector: an interpretative review. Journal of Human Resources 37, 696-727.

[17] Falk, A., Gächter, S., Kovács, J., 1999. Intrinsic motivation and extrinsic incentives in a repeated game with incomplete contracts. Journal of Economic Psychology 20, 251-284.

[18] Francois, P., 2000. 'Public service motivation' as an argument for government provision. Journal of Public Economics 78, 275-299.

[19] Frank, R.H., 1996. What price the moral high ground? Southern Economic Journal 63, 1-17.

[20] Frey, B.S., 1993. Shirking or work morale?: The impact of regulating. European Economic Review 37, 1523-1532.

[21] Frey, B.S., 1997a. Not Just for the Money. Edward Elgar Publishers, Cheltenham.

[22] Frey, B.S., 1997b. On the relationship between intrinsic and extrinsic work motivation. International Journal of Industrial Organization 15, 427-439.

[23] Frey, B.S., Jegen, R., 2001. Motivation crowding theory. Journal of Economic Surveys 15, 589-611.

[24] Frey, B.S., Kucher, M., Stutzer, A., 2001. Outcome, process, and power in direct democracy. Public Choice 107, 271-293.

[25] Fudenberg, D., Tirole, J., 1992. Game Theory. MIT Press, Cambrigde.

[26] Furnham, A., 1990. The Protestant Work Ethic. Routledge, London. 
[27] Glazer, A., 2004. Motivating devoted workers. International Journal of Industrial Organization 22, 427-440.

[28] Handy, F., Katz, E., 1998. The wage differential between nonprofit institutions and corporations: getting more by paying less? Journal of Comparative Economics 26, 246-261.

[29] Hansmann, H.B., 1980. The role of nonprofit enterprise. The Yale Law Journal 89, 835-901.

[30] Holmström, B., Milgrom, P., 1991. Multi-task principle-agent analysis: incentive contracts, asset ownership, and job design. Journal of Law, Economics and Organization 7, 24-52.

[31] Janssen, M.C.W., 2002. Catching hipo's: screening, wages, and competing for a job. Oxford Economics Papers 54, 321-333.

[32] Janssen, M.C.W., Mendys-Kamphorst, E., 2004. The price of a price: on the crowding out and in of social norms. Journal of Economic Behavior and Organization 55, 377-395.

[33] Jenkins, A., 2001. Companies' use of psychometric testing and the changing demand for skills: a review of the literature, CEE Discussion Paper, London.

[34] Keenan, T., 1995. Graduate recruitment in Britain: a survey of selection methods used by organizations. Journal of Organizational Behavior 16, 303-317.

[35] Lazear, E.P., 1995. Personnel Economics. MIT Press, Cambridge.

[36] Leete, L., 2001. Whither the nonprofit wage differential? Estimates from the 1990 census. Journal of Labor Economics 19, 136-170.

[37] Manning, A., 2003. Monopsony in Motion. Princeton University Press, Princeton.

[38] Montgomery, J.D., 1991. Equilibrium wage dispersion and interindustry wage differentials. Quarterly Journal of Economics 106, 163-179.

[39] Mortensen, D.T., Pissarides, C.A., 1999. New developments in models of search in the labor market. In: O. Ashenfelter and D. Card (Eds.), Handbook of Labor Economics, Vol. 3B. Elsevier Science B.V., Amsterdam pp. 2567-2627.

[40] Preston, A.E., 1989. The nonprofit worker in a for-profit world, Journal of Labor Economics 7, 438-463. 
[41] Quinn, R., Staines, G., 1979. The 1977 quality of employment survey: descriptive statistics with comparison data from the 1969-1970 and 1972-1973 surveys. Institute for Social Research, University of Michigan.

[42] Riley, J.G., 2001. Silver signals: twenty-five years of screening and signaling. Journal of Economic Literature 39, 432-478.

[43] Rose-Ackerman, S., 1996. Altruism, nonprofits and economic theory. Journal of Economic Literature 34, 701-728.

[44] Rosen, S., 1986. The theory of equalizing differences. In: O. Ashenfelter and R. Layard (Eds.), Handbook of Labor Economics, Vol. 1. Elsevier Science B.V., Amsterdam pp. 641-692.

[45] Rotemberg, J.J., 1994. Human relations in the workplace. Journal of Political Economy 102, 684-717.

[46] Ryan, A.M., Mc Farland, L., Baron, H., Page, R., 1999. An international look at selection practices: nation and culture as explanations for variability in practice. Personnel Psychology 52, 359-391.

[47] Seabright, P., 2002. Blood, bribes and the crowding-out of altruism by financial incentives. Mimeo, University of Toulouse.

[48] Shi, S., 2002. A directed search model of inequality with heterogeneous skills and skill-biased technology. Review of Economic Studies 69, 467491.

[49] Spence, A.M., 1973. Job market signaling. Quarterly Journal of Economics $90,355-374$.

[50] Weiss, A., 1990. Efficiency Wages: Models of Unemployment, Layoffs, and Wage Dispersion. Princeton University Press, Princeton. 